\title{
Performance Investigation of Single Path and Multi Path Routing Protocols in High Mobility MANETs
}

\author{
Suveg Moudgil \\ PhD Research Scholar, CSE Dept. \\ MMEC, M.M. University, Mullana
}

\author{
Sanjeev Rana, PhD \\ Professor, CSE Dept. \\ M.M. University, Mullana
}

\begin{abstract}
Mobile ad hoc networks are the collection of wireless nodes which communicate with each other without the support of centralized infrastructure. Due to frequent node mobility in high mobility MANETs, the network topology changes dynamically. Each node in MANET acts as host and router. A routing protocol is used to discover route between nodes. Robust routing protocol is needed to allow the nodes to communicate in high mobility MANETs. This paper investigates the performance of single path routing protocol AODV and multipath routing protocol AOMDV under different mobility conditions. Performance evaluation of these protocols showed that AOMDV protocol is more robust than AODV protocol due to its capability of finding and using alternate routes in case of a route failure in high mobility MANETs.
\end{abstract}

\section{Keywords}

AODV, AOMDV, Multipath Routing, Robust Routing.

\section{INTRODUCTION}

Mobile ad hoc networks are the networks which consist of mobile nodes that can communicate with each other without any fixed or predetermined infrastructure [1]. MANETs have the unique characteristics which include dynamic topology, bandwidth constrained links and limited energy of nodes [2]. Ad hoc networks can be applied anywhere at any time without infrastructure. Example applications o ad hoc networks includes military battlefield, emergency search and rescue operations, meeting and conventions in which a person want to make a quick connection for information sharing.

Routing protocols have a significant role in enabling communication in wireless ad hoc networks. Routing protocols can be classified as proactive, reactive and hybrid protocols [3]. Proactive or Table driven routing protocols keep up-to-date routing information in a routing table which is exchanged periodically or when network topology changes. Optimized link state routing (OLSR) [4] and destination sequenced distance vector (DSDV) [5] are well known proactive routing protocols. Reactive or on demand routing protocols creates route to the destination only when required. Examples of on demand routing protocols includes AODV [6], DSR [7] and TORA [8]. Hybrid routing protocols provides the benefits of proactive and reactive routing protocols. Zone routing protocol (ZRP) [9], Zone based hierarchical link state (ZHLS) [10] and Core extraction distributed ad hoc routing (CEDAR) [11] are examples of hybrid routing protocols.

A robust routing protocol is required to provide reliability and energy efficiency with low control overhead. The wireless medium dynamic nature, fast and unpredictable topological changes, limited battery power and mobility of nodes puts challenges in designing of the robust routing protocols. The routing protocols are classified in to two categories based on the no. of paths used between any source-destination pair. These are single path or uni-path routing protocol and multipath routing protocols. Multipath routing protocols finds multiple paths between any source-destination pair.

This paper investigates the performance of single path routing protocol AODV and multipath routing protocol AOMDV under different mobility conditions. We have evaluated the Performance of these protocols on the basis of different parameters which includes packet delivery ratio, average end to end delay and normalized routing overhead.

Rest of the paper is organized as follows. Section II gives brief background of single path and multipath routing protocols. Section III describes the simulation model and parameters. In Section IV, results are compared and analyzed. Section V presents the conclusion of the paper.

\subsection{LITERATURE REVIEW}

\subsubsection{Single Path Routing Protocols}

The single path routing protocols finds only a single path route between a source-destination pair [13]. A new route discovery is required in case of every route break. Single path routing protocols have route discovery and route maintenance phase. In route discovery phase a route is find out between any source-destination pair. Route maintenance phase consist of repairing a broken route or finding a new route in the presence of a route failure. The most common single path routing protocols are AODV [5], DSR [6] and DSDV [4] etc.

\subsubsection{AODV}

The Ad hoc On-Demand Distance Vector Routing (AODV) protocol is a reactive unicast routing protocol for MANETs. [6] [12] AODV maintains the routing information of active paths in routing tables at nodes. Each mobile node maintains a next hop routing table, which contains the destinations to which it currently has a route. AODV uses destination sequence number technique for ensuring loop freedom. In AODV, when a source node wants to send packets to the destination it checks its routing table for active routes to the destination. If no route is available, the source node initiates a route discovery procedure. In route discovery procedure, the source node broadcasts route request (RREQ) packets. The RREQ packet consist of source address, destination address, broadcast id, last seen sequence number of the destination and source node sequence number. Sequence numbers are essential to assure loop free and up-to-date routes. A route can be established when the RREQ reaches either the destination itself or an intermediate node with a fresh enough route to the destination. The intermediate nodes discards RREQs that it has seen before to reduce the flooding overhead. A route is selected with the highest destination sequence number in case of choice between multiple routes to the destination. The route is made available by unicasting the Route Reply RREP packet 
to the source node. Each node maintains a "precursor list" including the IP address for each its neighbors that are likely to use it as a next hop to each destination. Each route table entry in AODV have destination IP address, flags, destination sequence number, network interface, hop count, next hop, list of precursors, lifetime fields [12].

Upon receiving the RREQ, the destination or a node that has a route to the destination examines the destination sequence numbers it currently knows and the one specified in the RREQ. RREP packet is created and forwarded back to the source only if the destination sequence number is equal to or greater than the one specified in RREQ. Each intermediate node along the routes after getting the RREP packet, updates its next hop table entries with respect to the destination node. RREP packets with lower sequence number will be discarded. Node utilizes hello messages to announce its existence to its neighbors. When a node finds a link disconnection, it broadcast a route error (RERR) packet to its neighbors, which in turn forwards the RERR packet towards nodes whose routes may be affected by the disconnected link. Then the affected source can re-initiate a route discovery procedure if the route is still needed [12].

\subsection{Multipath Routing Protocols}

In multipath routing, more than one path is found and used between any source-destination pair [13]. It provides fault tolerance and load balancing [14] [15]. In case of route failure, an alternate path can be used, thus postponing the required route discovery. The Multipath routing protocols consist of route discovery, traffic allocation and path maintenance phases. Route discovery phase consist of finding multiple node disjoint or link disjoint routes between any source-destination pair. In traffic allocation phase, source starts sending data to destination along the multiple paths. Path maintenance phase consist of finding paths in case of link and/or node failure. Split Multipath Routing (SMR) [16], MSR [17], MPDSR [18], AOMDV [19], AODVM [20] are the examples of multipath routing protocols.

\subsubsection{AOMDV}

Ad hoc On-demand Multipath Distance Vector (AOMDV) is the enhanced version of AODV protocol [19]. It is an on demand and reactive protocol of ad hoc wireless networks. AOMDV computes multiple loop-free and link-disjoint paths between any source-destination pair during route discovery The AOMDV protocol has two main parts. A route update rule to discover and maintain multiple loop free paths at each node and a distributed protocol to find link disjoint paths. AOMDV protocol uses the concept of advertised hop count. The advertised hop count of a node $\mathrm{i}$ for a destination $\mathrm{d}$ describes the "maximum" hop count of the multiple paths for $\mathrm{d}$ available at I [19]. "Maximum" hop count is considered, as then the advertised hop count can never change for the same sequence number. The protocol only allows accepting alternate route with lower hop counts. The advertised hop count is initialized each time the sequence number is updated. A node $\mathrm{i}$ update its advertised hop count for a destination $\mathrm{d}$ whenever it sends a route advertisement for $\mathrm{d}$. The loop freedom is assured by electing the alternate path for destination on the grounds of the value of hop count of path is less than the advertised hop count for that destination. The destination node sorts all the paths by the maximum hop count value. The best paths are selected and data forwarded through these paths. AOMDV may follow node-disjoint or linkdisjoint routes. During route discovery, the source node broadcasts a Route Request packet throughout the network. Each recipient node creates multiple reverse routes while processing the Route Request packets that are received from multiple neighbors.

\section{SIMULATION MODEL}

We have used simulation model based on ns-2 [21]. Simulation area of $1200 \times 1200$ meters is used. No. of mobile nodes are 40 . The distributed coordination function (DCF) of IEEE 802.11 [22] for wireless LANs is used as MAC layer. Simulation runs for 200 seconds. Two ray ground propagation is used. Omni directional antenna is used for the simulation purpose. The Random Waypoint model [23] is used to model mobility. In this model, each node starts its journey from a random location to a random location at a randomly chosen time. Once a destination is reached, another random destination is chosen after the predetermined time called as pause time. We consider different mobility speed of mobile nodes in the range of $1,10,30,40,50 \mathrm{~m} / \mathrm{s}$. We vary the pause time from $0,4,8$ and $20 \mathrm{sec}$. We simulate four different scenarios with different pause time as the base parameters and vary the mobility speed of nodes. CBR (Constant Bit Rate) sources are used as traffic sources. The source and destination pair are spread randomly over the network. Packet size is 512 bytes. The no. of connections and packet sending rate are kept constant. All traffic conditions are established at random times.

\subsection{Simulation Parameters}

Simulation parameters are summarized in the table given below.

Table 1: Simulation parameters

\begin{tabular}{|l|l|}
\hline Parameter & Value \\
\hline Simulation Area & 1200 x 1200 \\
\hline Channel Type & Wireless \\
\hline Simulation Time & 200 Seconds \\
\hline MAC Type & 802.11 \\
\hline Antenna Model & Omni \\
\hline Radio Propagation Model & Two Ray Ground \\
\hline Traffic Type & CBR \\
\hline Interface Queue Length & 50 \\
\hline Interface Queue Type & DropTail/Priqueue \\
\hline No. of Nodes & 40 \\
\hline Mobility Model & Random Way Point \\
\hline Mobility Speed & $1,10,20,30,40,50$ \\
\hline No. of Connections & 30 \\
\hline
\end{tabular}

\section{PERFORMANCE PARAMETERS AND RESULTS ANALYSIS}

Packet delivery ratio, average end to end delay and normalized routing overhead are selected to evaluate the performance of single path AODV and multipath AOMDV routing protocol.

\subsection{Packet Delivery Ratio}

It is calculated by dividing the no. of data packets delivered to the destination by the no. of packets generated by the CBR sources. The following graphs shows the PDR under the 4 different pause time scenarios with different mobility speeds. 


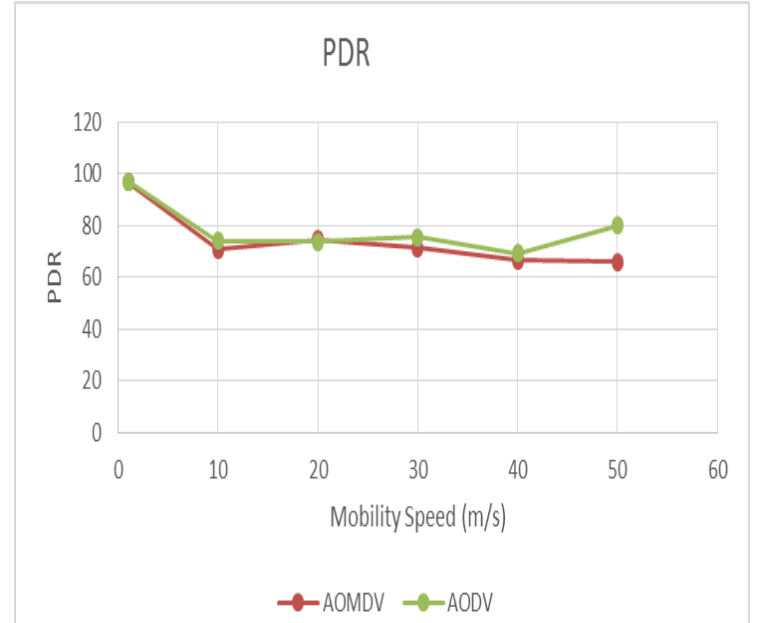

Figure 1: pdr versus mobile speed when pause time is $\mathbf{0 .}$

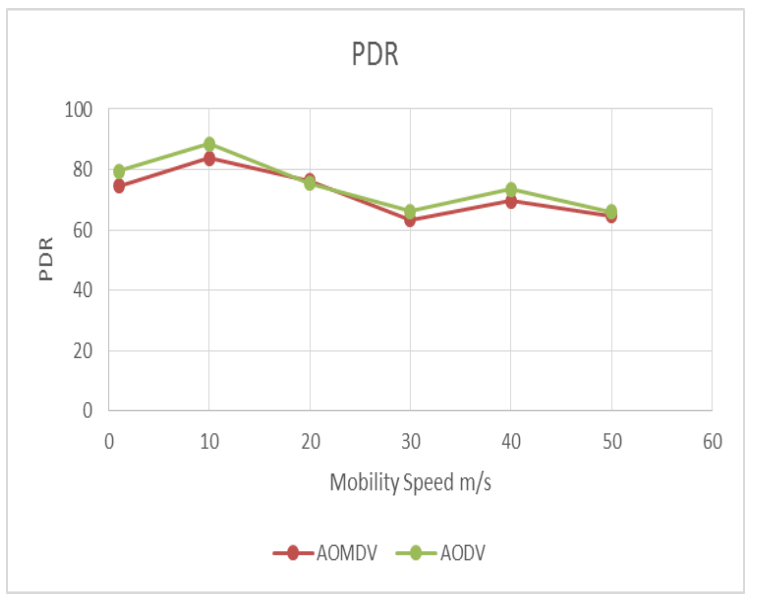

Figure 2: pdr versus mobile speed when pause time is 4 .

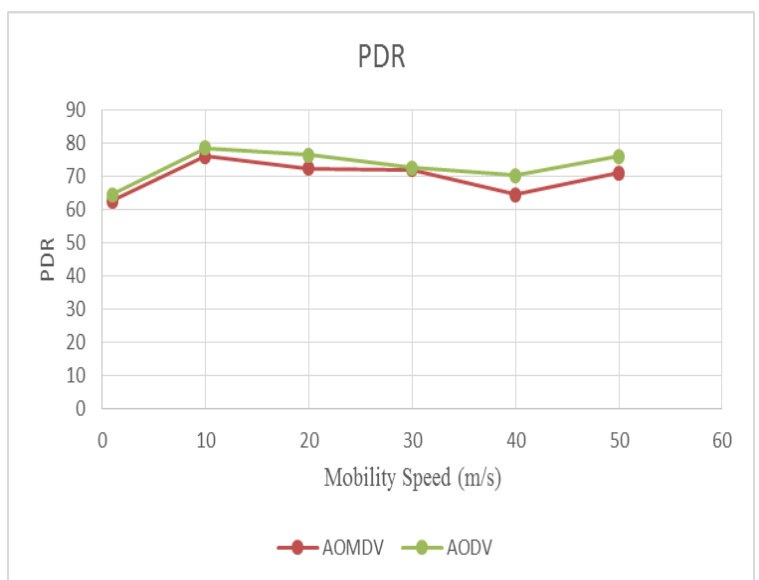

Figure 3: pdr versus mobile speed when pause time is 8 .

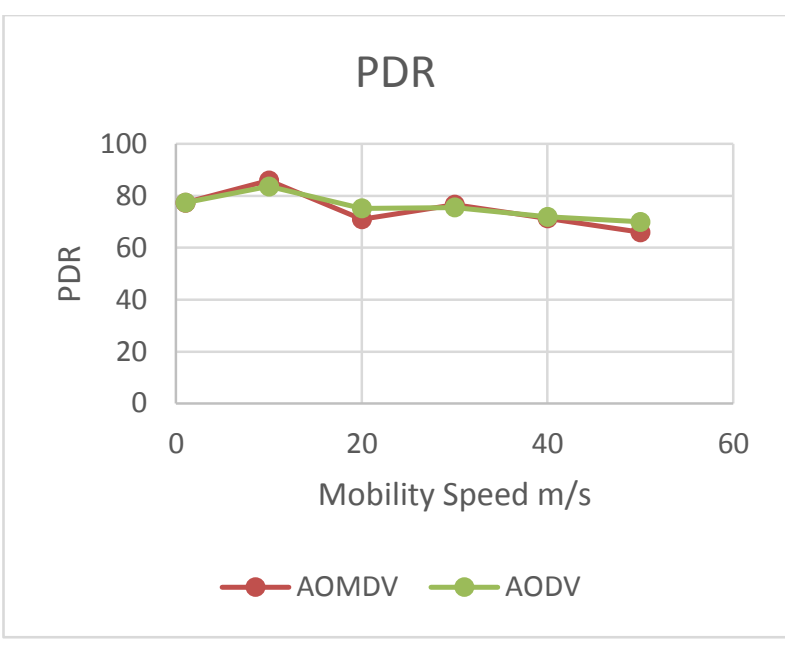

Figure 4: pdr versus mobile speed when pause time is $\mathbf{2 0}$.

\subsection{Average End to End Delay}

It is the total time taken by each packet to reach the destination. It includes all delays such as buffering during route discovery, queuing at the interface queue, retransmision delay at the MAC layer, propagation and transfer time.

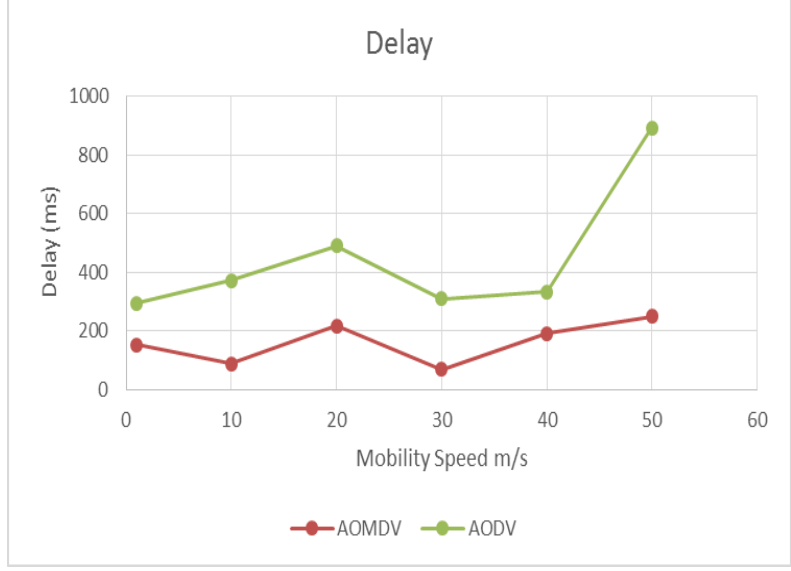

Figure 5: Average end to end delay versus mobility speed when pause time is 0 .

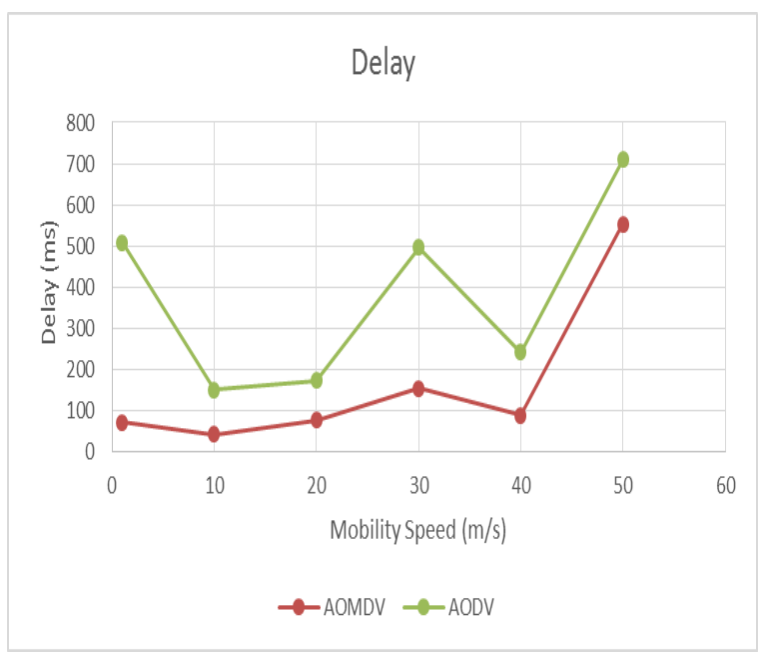

Figure 6: Average end to end delay versus mobility speed when pause time is 4 


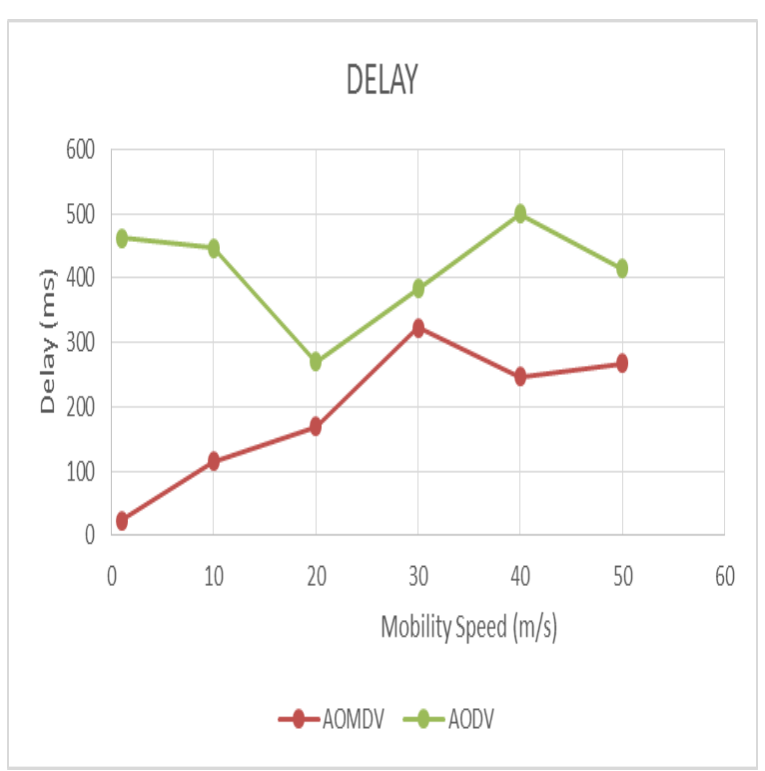

Figure 7: Average end to end delay versus mobility speed when pause time is 8

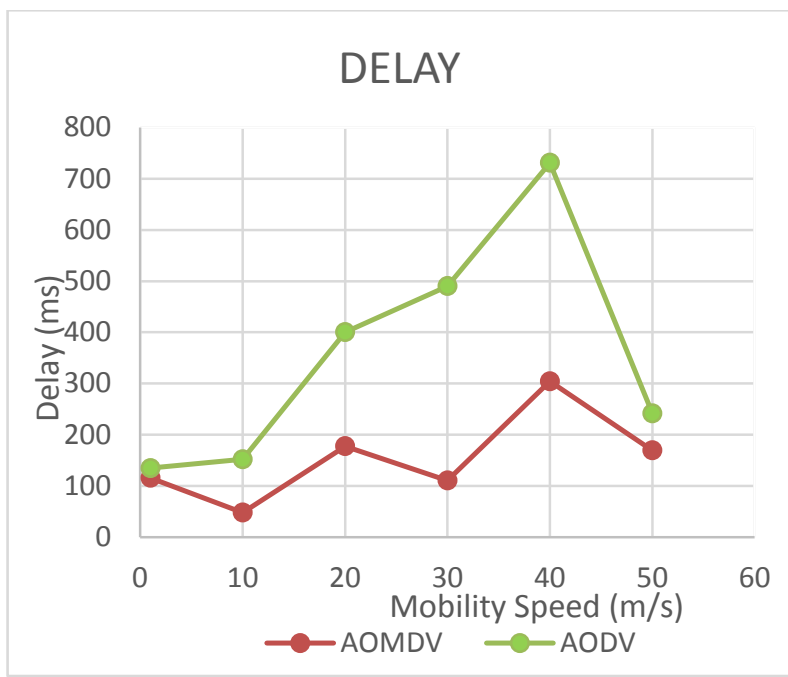

Figure 8: Average end to end delay versus mobility speed when pause time is 20 .

\subsection{Normalized routing overhead}

It is the ratio of no. of routing packets transmitted per data packet delivered at the destination. Each hop wise transmission of a routing packet is counted as one transmission.

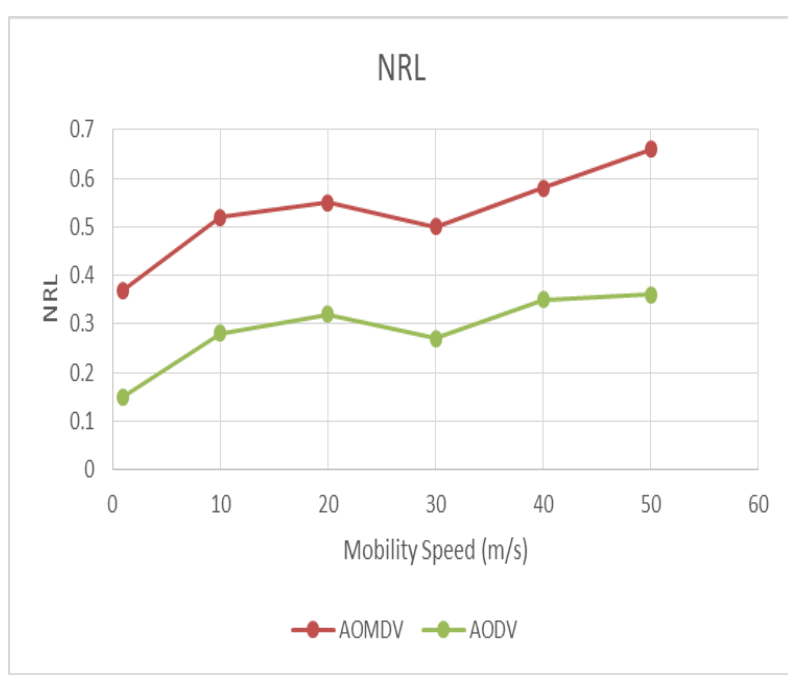

Figure 9: Normalized routing overload versus versus mobility speed when pause time is 0 .

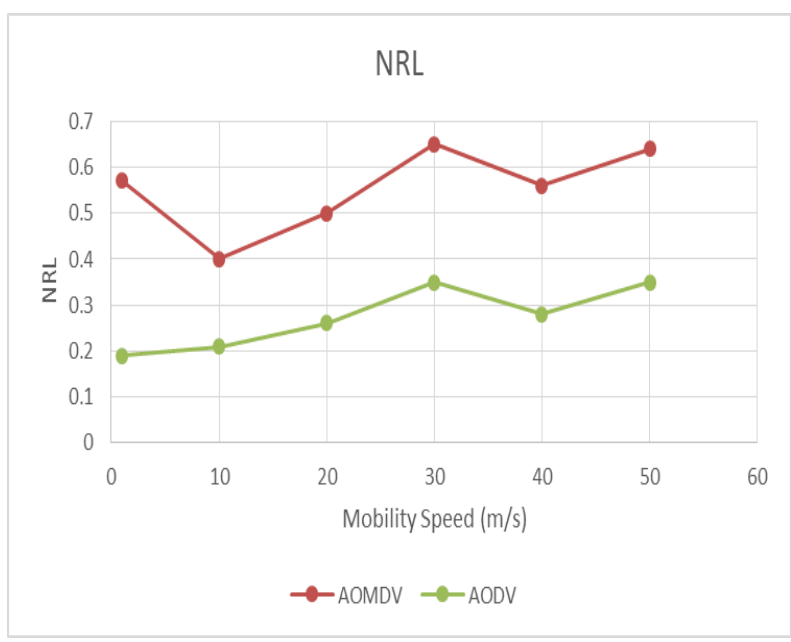

Figure 10: Normalized routing overload versus versus mobility speed when pause time is 4 .

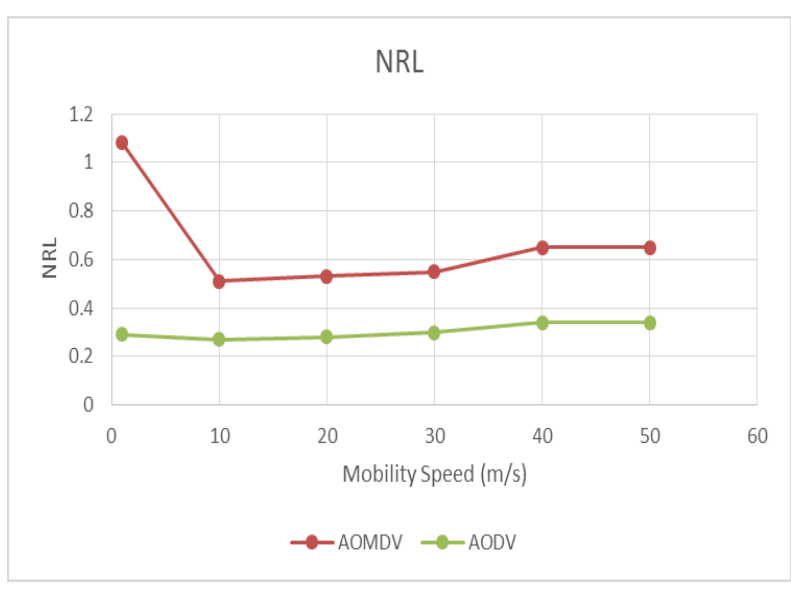

Figure 11: Normalized routing overload versus versus mobility speed when pause time is 8 . 


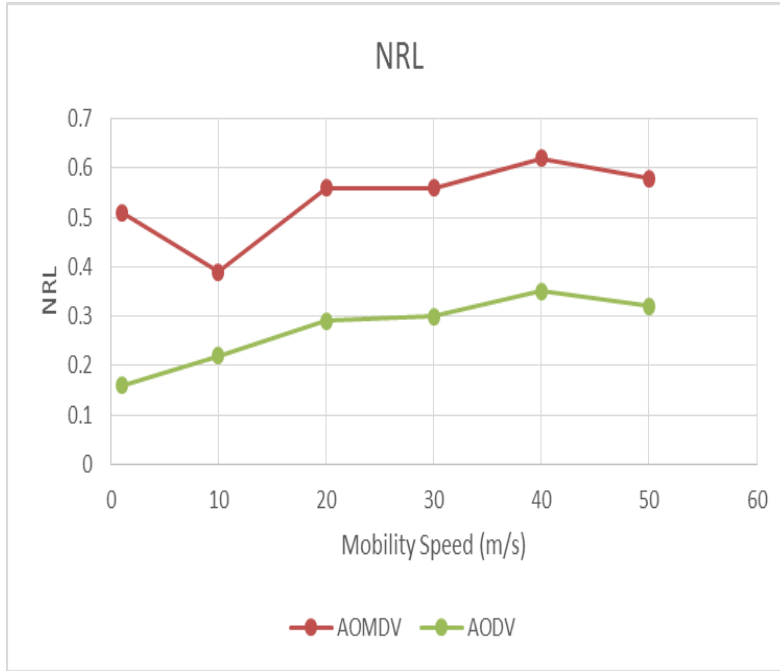

Figure 12: Normalized routing overload versus versus mobility speed when pause time is 20 .

\section{CONCLUSION}

This paper invetigates the performance of single path routing protocol AODV and multipath routing protocol AOMDV under different mobility conditions using NS 2.35 simulator. Node are simulated with different mobility speeds with different pause times. Packet delivery ratio, end to end delay and network routing load are considered for comparing the AODV and AOMDV protocols. In high mobility MANETs, AOMDV protocol proves to be more robust than AODV due to its ability to search for alernate route when current links breaks. Routing overhead of AOMDV protocl is more due to its alternate route discovery mechanism. Hence we can conclude that in high mobility MANETs, AOMDV gives better performance then AODV as it has better PDR and less average end to end delay but it has more routing overhead.

\section{REFERENCES}

[1] J. Loo, J. L. Mauri, J. H. Oritz, "Mobile A d Hoc Networks: Current Status and Future Trends", CRC Press, 2016.

[2] C. S. R. Murthy and B. S. Manoj, "Ad Hoc Wireless Networks: Architecture and Protocols", Pearson Education, Sep 2004.

[3] E. M. Royer and C. K. Toh, "A Review of Current Routing Protocols for Ad Hoc Mobile Wireless Networks", IEEE Personal Communications, pp 46-55, April 1999.

[4] T. Clausen, C. Dearlove, P. Jacquet and U. Herberg, " The Optimized Link State Routing Protocol Version 2", IETF, RFC 7181, Sep. 2014.

[5] C. E. Perkins and P. Bhagwat, "Highly Dynamic Destination Sequenced Distance Vector Routing (DSDV) for Mobile Computers", ACM SIGCOMM, pp 234-244, 1994.

[6] C. Perkins and E. Belding Royer, "Ad hc On-Demand Distance Vector (AODV) Routing”, IETF, RFC 3561, 2003.

[7] D. Johnson, Y. Hu and D. Maltz, "The Dynamic Source Routing Protocol (DSR) for Mobile Ad Hoc Networks", IETF, RFC 4728, Feb 2007.
[8] V. Park, S. Corson, "Temporally Ordered Routing Algorithm (TORA) Version 1 Fuctional Specifications",IETF, draft-ietf-manet-tora-spec-oo.txt, May 1997.

[9] Z. J. Haas, M. R. Pearlman, "The Zone Routing Protocol (ZRP) for Ad Hoc Networks", IETF, draft-zone-routingprotocol-00.txt, Nov. 1997.

[10] C. C. Chiang, T. C Tsai, W. Liu and M. Gerla, ' Routing in clustered multihop mobile wireless networks with fading channel", IEEE SICON, 1997.

[11] P. Sinha, R. Sivakumar and V. Bharghaven, "CEDAR: Core Extraction Distribution Ad Hoc Routing Algorithm”, IEEE INFOCOMM, March 1999.

[12] C.E Perkins and E. M. Royer, "Ad Hoc On Demand Distance Vector Routing", In proceedings of the $2^{\text {nd }}$ IEEE Workshop on Mobile Computing Systems and Applications, pp, 1999.

[13] V.C Patil, Rajashree V. Biradar, R.R Mudholkar, S. R. Sawant, "On-Demand Multipath Routing protocols for Mobile Ad Hoc Networks Issues and Comparison", International Journal of Wireless Communication and Simulation, Vol. 2, Issue 1, pp 21-38, 2010.

[14] M. Tarique, K. E. Tepe, S. Abidi and S. Erfani, "Survey of Multipath Routing Protocols for Mobile Ad Hoc Networks", ELSEVIER Journal of Network and Computer Applications, Nov. 2009.

[15] I. Cidon, R. Rom and Y. Shavitt, "Analysis of Multipath routing”, IEEE Transactions on Networking, pp 885-896, 1999.

[16] S. J. Lee and M. Gerla, "Split multipath routing with maximally disjoint paths in ad hoc networks", technical report, Computer Science Department, University of California, Los Angeles, Aug. 2000.

[17] L. Wang, L. Zhang, Y. Shu Dong, "multipath source routing in wireless ad hoc networks" in proceedings of canadian conference on electrical and computer engineeirng, Vol. 1, pp 479-83, 2000.

[18] S. Ahn, "DSR Extension for Multipath Routing", IETF, draft-ahn-manet-multipath-dsr-00.txt, Dec. 2015.

[19] M. K. Marina and S. R. Das, "On-demand Multipath Distance Vector Routing in Ad Hoc Networks", Wiley Interscience, pp 969-988, 2006.

[20] Z. Ye, S. V. Krishnamurthy, S. K. Tripathi, “ A framework for reliable routing in mobile ad hoc networks" in proceeding of $22^{\text {nd }}$ annual joint conference of the IEEE computer and communication societies (INFOCOM), Vol. 1, pp 270-80, 2003.

[21] "Network Simulator, NS-2", available online at http://www.isi.edu/nsnam/ns

[22] "Wireless LAN medium access control (MAC) and physical layer (PHY) specifications", IEEE standards 802.11, 1997.

[23] T. Camp, J. Boleng and V. Davies, "A Survey of Mobility Models for Ad Hoc Network Research", Wireless Communication and Mobile Computing (WCMC): Special issue on Mobile Ad Hoc Networking: Research, Trends and Applications, Vol. 2, No. 5, p. 483$502,2002$. 